\title{
Different Mechanisms Underlie Post-menarchial Increase in Depression and Weight
}

\author{
Eveline J. Wouters • Junilla K. Larsen • \\ Judith S. Dubas • Rinie Geenen
}

Published online: 7 September 2010

(C) The Author(s) 2010. This article is published with open access at Springerlink.com

\begin{abstract}
Background Depression and being overweight are correlated health problems in adulthood. Adolescence is a significant period for the onset and increase of depression and obesity, especially among girls. Pubertal development also occurs with concomitant increases in weight. Thus, it is not yet clear whether the association between depression and being overweight can be explained by pubertal development.

Purpose We examined the association between depressive mood, body weight, and pubertal status in adolescent girls. Method The design was cross-sectional. In 962 young adolescent Dutch girls (age range, 11.9-15.9) weight and height measurements were used to calculate height, age, and
\end{abstract}

\section{E. J. Wouters $(\bowtie)$}

Fontys University of Applied Sciences,

P.O. Box 347, 5600 AH Eindhoven, The Netherlands

e-mail: e.wouters@fontys.nl

\section{E. J. Wouters}

Clinical Psychology section, Tilburg University,

Tilburg, The Netherlands

\section{J. K. Larsen}

Behavioural Science Institute, Radboud University Nijmegen, Nijmegen, The Netherlands

\section{J. S. Dubas}

Department of Developmental Psychology, Utrecht University,

Utrecht, The Netherlands

\section{R. Geenen}

Department of Clinical and Health Psychology,

Utrecht University,

Utrecht, The Netherlands

\section{R. Geenen}

Department of Rheumatology and Clinical Immunology, University Medical Center Utrecht,

Utrecht, The Netherlands gender-standardized body weight (zBMI). Questionnaires assessed depressive mood (the Center for Epidemiological Studies-Depression, CES-D, inventory) and menarcheal status (pre or post).

Results The correlation between menarcheal status and body weight $(r=0.34, p<0.001)$ was not affected by depressive mood, and the correlation between menarcheal status and depressive mood $(r=0.20, p<0.001)$ was not affected by body weight. A small correlation between depressive mood and body weight $(r=0.12, p<0.01)$ largely disappeared after controlling for menarche.

Conclusion Menarcheal status largely explains the association between weight and depression. It is independently associated with both BMI and depression, suggesting that different mechanisms underlie the post-menarcheal increased prevalence of depression and overweight.

Keywords Adolescence - Body mass index · Body weight . Depression $\cdot$ Menarche

\section{Introduction}

Overweight and depression are prevalent health problems $[1,2]$ that are correlated with each other in adulthood, especially among women [3, 4]. Associations between adolescent overweight and adult depression $[5,6]$ as well as between adolescent depression and adolescent and adult overweight [7-9] have been observed. Several mechanisms may explain these associations: being overweight may facilitate the development of depression due to low self-esteem and body dissatisfaction [10], and depression may facilitate becoming overweight due to reduced physical activity [11], increased eating [12], reduced selfregulatory strength [13], and low self-efficacy [14]. 
Moreover, similar biological mechanisms such as predisposing genotypes [2] and the neuroendocrine system [15, 16] may be involved in both the development of depression and becoming overweight. Although multiple explanations have been suggested, the association between depression and being overweight is not consistently established [17, 18].

Adolescence is a significant period for the onset and increase in both depression and obesity, especially among girls $[19,20]$. Findings from the separate research fields investigating depression and overweight suggest that pubertal status, rather than age, is implicated in the increasing prevalence of both depression and obesity in adolescence, with this influence being most apparent among girls and in advanced pubertal stages [21-24]. To date, only one study simultaneously examined and verified an association between puberty, actual depression, and obesity [25]. The aim of our cross-sectional study was to gain further insight into the possible overlapping associations of puberty with both increased depressive mood and body weight. To clarify whether the association between depression and weight could be explained by pubertal status, we examined in adolescent girls the depression-corrected association between puberty and weight, the weight-corrected association between puberty and depression, and the puberty-corrected association depression and weight. We conducted these analyses to verify that the link between puberty and being overweight was not an artifact of depression and that the link between puberty and depression was not an artifact of being overweight. Menarcheal status, as a clearly identifiable stage of pubertal development and physical measures of weight and height were used.

\section{Methods}

Design and Procedure

A cross-sectional design was used. Data from the current study were drawn from the baseline data that are collected as part of an ongoing study entitled the "Mental Health and Health Habits" study. Seven high schools in the Netherlands participated; three schools were located in cities and four were located in the suburbs of these cities. An information letter describing the goal and procedure of the study was sent to the parents $(N=2,216)$ who either e-mailed or telephoned the research office if they did not consent to their child's participation. A sample of 2,051 adolescents (1,056 boys and 995 girls) completed the first wave of data collection, with nonparticipation resulting from parental or participants' denied consent, absence on the day of testing, or moving out of the school system. Details of the study have been described elsewhere [26]. For the purpose of the present study, only the data of the girls were analyzed. Schools were visited by trained researchers and graduate students from February until May 2007. A ten-page questionnaire was completed by adolescents during regular lesson time in the presence of a researcher. Weight and height measurements were performed individually out of sight of classmates. For confidentiality, a numeric code was used to identify adolescents. The study was approved by the Institutional Ethical Committee (Radboud University Nijmegen).

\section{Participants}

Participants were adolescent girls who followed regular secondary education (high school) in the Netherlands. The mean age of the girls was 13.8 years (standard deviation 0.7 ; range, 11.9-15.9) and the mean body mass index (BMI, the weight divided by the square of the height in meters) was $20.0 \mathrm{~kg} / \mathrm{m}^{2}$ (standard deviation 2.9, range 13.6-32.0). The majority of the girls (95\%) were of Dutch origin.

\section{Measurements}

Body Weight Height was measured to the nearest $0.5 \mathrm{~cm}$ (Seca 214) and weight to the nearest $0.1 \mathrm{~kg}$ (Mettler PM 3000 ) with participants wearing light clothes and no shoes. Age was calculated to the nearest month from the date of birth and date of measurement of participants. Using the Centers for Disease Control and Prevention data, age- and gender-standardized BMI scores (zBMI) were calculated [27].

Depressive Mood To measure depressive mood, the Dutch version of the Center for Epidemiological StudiesDepression (CES-D) inventory was used. This 20-item self-report scale has been used and found suitable for adolescents [28] and has recently been validated in a large Dutch sample [29].

Pubertal Development Menarcheal status was determined dichotomously by asking in the self-report questionnaire "have you begun to menstruate?" with the answering possibility "yes" and "no". Menarche is a relatively late, but objective pubertal event occurring in the majority of cases when at least Tanner stage 4 on breast development has been attained [30].

Education Level Participants' current education level was assessed on a 7-point scale, with levels 1 and 2 reflecting pre-vocational education; levels 3,4 , and 5 intermediate education; and levels 6 and 7 pre-university education. 


\section{Statistical Analyses}

To examine the association between pubertal status, depressive mood and body weight among adolescent girls, two bivariate correlation coefficients were calculated between each possible set of two variables: one with and one without partialling out the effect of the other (third) variable. These analyses show: (1) whether or not depressive mood affects the correlation between body weight and menarcheal status, (2) whether or not body weight affects the correlation between depressive mood and menarcheal status, and (3) whether or not the correlation between body weight and depressive mood is affected by the effect of menarcheal status. All correlations included a control for education level. To further test whether or not the third variable explained the correlations between the two other variables, mediational analyses according to common procedures were applied [31]. In the first step, the association between predictor and potential mediator was determined. In the next step, regression analysis was performed to test the association between predictor and outcome variable, controlling for the mediator. If the association was reduced significantly (using the Sobel test), this was considered to indicate mediation.

The score distributions of zBMI and education level were normal (skewness $<1$ ). Because the score distribution of depressive mood (CES-D) was positively skewed (1.62), these scores were changed by logarithmic transformation (base $_{10} \log$ ) with a constant of 1 added to the values.

All significance tests were two-tailed and $p$ values less than 0.05 were considered to be significant. Analyses were performed using SPSS version 16.

\section{Results}

\section{Characteristics}

Of the sample of 995 girls, 962 subjects (97\%) with complete data on the variables of interest were included in the analyses. This was done to be able to compare all data. The groups with complete and incomplete measurements showed no differences with respect to education level, zBMI, depressive mood, and menarche. Table 1 shows the descriptive statistics for the final sample. The depression (CES-D) scores for girls in our sample were comparable to the scores of a recent Dutch school sample [29]. The percentage of overweight adolescents in our sample (13\%) was lower than the Dutch adolescent population (17\%) [32].

\section{Correlational Analyses}

Figure 1 displays the correlations between zBMI, depressive mood (CES-D), and menarche before and after adjustment for the other variable. All analyses were corrected for education level.

The correlation between zBMI and menarche was of moderate magnitude and highly significant $(r=0.34$, $p<0.001)$. The correlation remained similar after removal of the effect of depressive mood $(r=0.33, p<0.001)$. The Sobel test $(p=0.12)$ confirmed that depressive mood did not play a role in the correlation between zBMI and menarche.

The correlation between depressive mood and menarche was of small magnitude and highly significant $(r=0.20$, $p<0.001)$. This correlation hardly changed after removal of the effect of zBMI $(r=0.17, p<0.001)$. The Sobel test $(p=0.07)$ confirmed that zBMI did not play a role in the correlation between depressive mood and menarche.

The correlation between depressive mood and zBMI was of small magnitude, though significant with this large sample size $(r=0.12, p=0.002)$. This correlation was significantly reduced after removal of the effect of menarche resulting in an almost zero correlation $(r=0.05$, $p=0.11)$. The Sobel test confirmed that the small correlation between depressive mood and zBMI was significantly explained by menarche $(p<0.001)$.

\section{Discussion}

Our study showed that menarcheal status of adolescent girls was related to both body weight (zBMI) and depressive mood but that these associations were independent of the other variable. That is, the link between menarcheal status and weight was not explained by depression nor was the link between menarcheal status and depression explained by weight. We did find a weak link between depressive mood and zBMI but this was explained by menarcheal status.
Table 1 Descriptive statistics of 962 adolescent girls

\begin{tabular}{lcc}
\hline & $\begin{array}{l}\text { Pre-menarcheal } \\
(n=272)\end{array}$ & $\begin{array}{l}\text { Post-menarcheal } \\
(n=690)\end{array}$ \\
\hline Age: mean \pm SD (range) & $13.3 \pm 0.7(11.9-15.2)$ & $14.0 \pm 0.6(12.2-15.9)$ \\
Education level: mean \pm SD (range) & $5.4 \pm 1.9(1-7)$ & $4.8 \pm 2.2(1-7)$ \\
Standardized weight (zBMI): mean \pm SD (range) & $-0.37 \pm 0.92(-3.10-2.00)$ & $0.28 \pm 0.74(-2.30-2.09)$ \\
Depressive mood (CES-D): mean \pm SD (range) & $8.1 \pm 7.1(0-45)$ & $12.2 \pm 9.7(0-52)$ \\
\hline
\end{tabular}




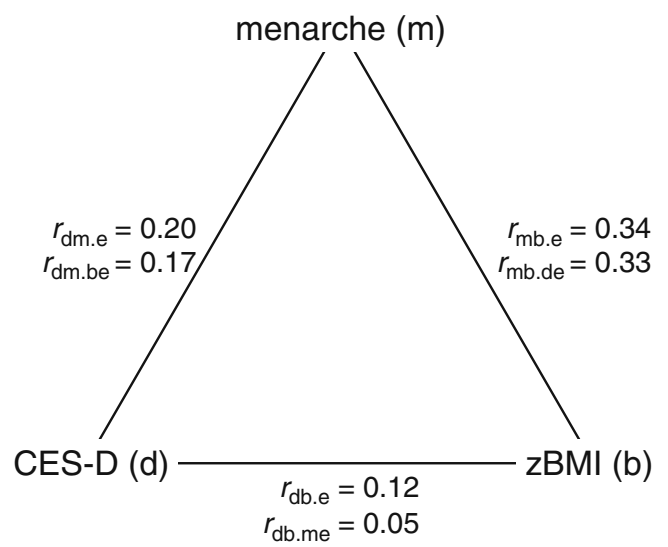

Fig. 1 Partial correlations $(r)$ between age and gender-standardized BMI $(z B M I, b)$, depressive mood $(C E S-D, d)$, and menarche (yes/no, $m$ ) before (top) and after (bottom) adjustment for the other (third) variable. All correlations were adjusted for education level (e)

Advances in pubertal development in girls are accompanied by rises in body weight. Puberty rather than age has been observed to be important for the subsequent development of excess weight $[22,33]$. The observations in our cross-sectional study are in agreement with these observations from longitudinal studies. The correlation between menarcheal status and body weight was of moderate magnitude and several reasons may underlie this correlation. First, as girls mature they tend to become less physically active [34] and show less healthy dietary behavior [35], both of these changes may lead to increases in weight. Because of the slowing of growth in height after menarche any weight gain results in excess body mass. Thus, puberty-related changes in behavior result in increases in body mass. Second, overweight in young girls is associated with earlier onset of puberty [36], and a shared genetic predisposition may affect both sexual maturation and the development of obesity [37]. Hence, puberty and weight-related changes may be linked with a third factor. While this third factor might be a genetic predisposition [38], the results from our study demonstrate that depressive mood does not underlie the correlation between menarcheal status and body weight.

Adolescence is also accompanied by higher rates of depression in girls [19]. Maturation of the hypothalamicpituitary gonadal axis has been postulated as a possible underlying mechanism for both being overweight and developing depression [21]. However, instead of being activated simultaneously as a result of pubertal changes, depression may be linked with hypothalamic-pituitary activity $[15,39]$ in different ways and at different times than obesity. Complementary to biological factors, psychosocial variables like father absence can result in both depression and early menarche $[21,40,41]$. This shows that pubertal development is a biological phenomenon that can be affected by the psychosocial context. The increased likelihood of multiple, simultaneous social changes occurring during the adolescent period (in school, friends, and family), together with increased vulnerabilities resulting from cognitive (e.g., body objectification consciousness) and affective (emotional reactivity) changes coupled with simultaneous pubertal changes all coalesce to increase the risk of depression among adolescent girls [42, 43]. Our analyses showed that although menarcheal status was correlated to both body weight and depressive mood, these associations were not affected when controlling for the other variable. That is, the link between menarcheal status and body weight was not affected when depression was controlled, nor was the link between menarcheal status and depression affected when body weight was controlled. This convincingly suggests that separate mechanisms play a role in the association between puberty and body weight and the association between puberty and depressive mood in adolescent girls.

Although several studies have found a correlation between depression and overweight in adult women $[3,4$, 44], the concomitant occurrence of adolescent depression and overweight is far less clear [45]. Likewise, in our study, the association between depressive mood and body weight was found to be weak. This might be considered unexpected, because obesity in adolescence predicts adult depression and depression in adolescence predicts adult obesity [5-8, 46]. These associations, however, involve a time lag. The combined results of a non-significant cross-sectional association between weight and depressive mood in the present study and significant prospective adolescence-adult associations in another suggest that the one problem (such as depression) may induce the other problem (overweight) only after some time. For instance, reduced physical activity and increased eating may explain why depressive mood prospectively predicts obesity [2]. Alternatively, the development of being overweight and depression may follow different timetables. The weak correlation between body weight and depressive mood in our study largely disappeared after controlling for menarche. In contrast, a previous study - with cross-sectional correlations being of similar magnitude as in our study - found that the strength of the association between depression and obesity did not change with pubertal development [25]. Possible explanations are different measurements and definitions of pubertal status (five stages based on various secondary sexual characteristics versus menarcheal status), the indicator of weight (obesity cut-off scores versus a continuous measure), and depressive mood (Symptom Checklist-90 versus CES-D). The different findings and the relative lack of such studies suggest that more research is necessary to clarify the influence of puberty on depression and body weight. 
Our study has strengths and weaknesses. Strengths of our study include the large sample size and the use of objective weight and height measurements instead of self reports. One limitation is the cross-sectional study design. Although causal inferences cannot be drawn from correlations, rejection of causal relationships is indicated by the absence of association. Future longitudinal research measuring depressive mood and weight change will give more information about the temporal relationship between development of overweight and depressive mood in adolescent girls. A second possible limitation of our study is that we used menarcheal status as a measure of pubertal stage. This is a relatively late pubertal event and a rough measure of pubertal stage [47]. An advantage of this measure is that it is an accurately reported and a more objective measure than secondary sexual characteristics such as breast development stage. A third limitation is that we did not have information on socio-economic status, although we used education level as a rough proxy. Finally, our depressive mood scores were not dissimilar from other studies [29], but the percentage of overweight in our sample was somewhat below the Dutch average [32], a difference that may be due to the relatively high education level of our sample.

In conclusion, we found independent associations of menarche with both BMI and depression, suggesting that different mechanisms underlie the post-menarcheal increased prevalence of depression and overweight. Further research is needed to identify these mechanisms.

Acknowledgments This study was financed by the Netherlands Organization for Scientific Research (NWO) Veni Grant 451-05-013.

Open Access This article is distributed under the terms of the Creative Commons Attribution Non-Commercial License which permits any non-commercial use, distribution, and reproduction in any medium, provided the original author(s) and source are credited.

\section{References}

1. Carney RM, Freedland KE, Steinmeyer B, Blumenthal JA, Berkman LF, Watkins LL, et al. Depression and five year survival following acute myocardial infarction: a prospective study. J Affect Disord. 2008;109:133-8.

2. Faith MS, Matz PE, Jorge MA. Obesity-depression associations in the population. J Psychosom Res. 2002;53:935-42.

3. Heo M, Pietrobelli A, Fontaine KR, Sirey JA, Faith MS. Depressive mood and obesity in US adults: comparison and moderation by sex, age, and race. Int J Obes. 2006;30:513-9.

4. Strine TW, Mokdad AH, Dube SR, Balluz LS, Gonzalez O, Berry JT, et al. The association of depression and anxiety with obesity and unhealthy behaviors among community-dwelling US adults. Gen Hosp Psychiatry. 2008;30:127-37.

5. Mustillo S, Worthman C, Erkanli A, Keeler G, Angold A, Costello EJ. Obesity and psychiatric disorder: developmental trajectories. Pediatrics. 2003;111:851-9.

6. Anderson SE, Cohen P, Naumova EN, Jacques PF, Must A. Adolescent obesity and risk for subsequent major depressive disorder and anxiety disorder: prospective evidence. Psychosom Med. 2007;69:740-7.

7. Blaine B. Does depression cause obesity?: a meta-analysis of longitudinal studies of depression and weight control. J Health Psychol. 2008;13:1190-7.

8. Liem ET, Sauer PJ, Oldehinkel AJ, Stolk RP. Association between depressive symptoms in childhood and adolescence and overweight in later life: review of the recent literature. Arch Pediatr Adolesc Med. 2008;162:981-8.

9. Goodman E, Whitaker RC. A prospective study of the role of depression in the development and persistence of adolescent obesity. Pediatrics. 2002;110:497-504.

10. Franklin J, Denyer G, Steinbeck KS, Caterson ID, Hill AJ. Obesity and risk of low self-esteem: a statewide survey of Australian children. Pediatrics. 2006;118:2481-7.

11. Cassidy K, Kotynia-English R, Acres J, Flicker L, Lautenschlager NT, Almeida OP. Association between lifestyle factors and mental health measures among community-dwelling older women. Aust N Z J Psychiatry. 2004;38:940-7.

12. Simon GE, Ludman EJ, Linde JA, Operskalski BH, Ichikawa L, Rohde $\mathrm{P}$, et al. Association between obesity and depression in middle-aged women. Gen Hosp Psychiatry. 2008;30:32-9.

13. Muraven M, Baumeister RF, Tice DM. Longitudinal improvement of self-regulation through practice: building self-control strength through repeated exercise. J Soc Psychol. 1999;139:446-57.

14. Linde JA, Jeffery RW, Levy RL, Sherwood NE, Utter J, Pronk NP, et al. Binge eating disorder, weight control self-efficacy, and depression in overweight men and women. Int J Obes Relat Metab Disord. 2004;28:418-25.

15. Bornstein SR, Schuppenies A, Wong ML, Licinio J. Approaching the shared biology of obesity and depression: the stress axis as the locus of gene-environment interactions. Mol Psychiatry. 2006;11:892-902.

16. Lu XY. The leptin hypothesis of depression: a potential link between mood disorders and obesity? Curr Opin Pharmacol. 2007;7:648-52.

17. Pine DS, Goldstein RB, Wolk S, Weissman MM. The association between childhood depression and adulthood body mass index. Pediatrics. 2001;107:1049-56.

18. Friedman MA, Brownell KD. Psychological correlates of obesity: moving to the next research generation. Psychol Bull. 1995;117:3-20.

19. Nolen-Hoeksema S, Girgus JS. The emergence of gender differences in depression during adolescence. Psychol Bull. 1994;115:424-43.

20. Harding S, Maynard MJ, Cruickshank K, Teyhan A. Overweight, obesity and high blood pressure in an ethnically diverse sample of adolescents in Britain: the Medical Research Council DASH study. Int J Obes. 2008;32:82-90.

21. Angold A, Costello EJ. Puberty and depression. Child Adolesc Psychiatr Clin N Am. 2006;15:919-37.

22. Bini V, Celi F, Berioli MG, Bacosi ML, Stella P, Giglio P, et al. Body mass index in children and adolescents according to age and pubertal stage. Eur J Clin Nutr. 2000;54:214-8.

23. Brooks-Gunn J, Warren MP. Biological and social contributions to negative affect in young adolescent girls. Child Dev. 1989;60:40-55.

24. Ellis BJ, Essex MJ. Family environments, adrenarche, and sexual maturation: a longitudinal test of a life history model. Child Dev. 2007;78:1799-817.

25. Richardson LP, Garrison MM, Drangsholt M, Mancl L, LeResche L. Associations between depressive symptoms and obesity during puberty. Gen Hosp Psychiatry. 2006;28:313-20.

26. Larsen JK, Otten R, Engels RC. Adolescent depressive symptoms and smoking behavior: the gender-specific role of weight concern and dieting. J Psychosom Res. 2009;66:305-8. 
27. Ogden CL, Kuczmarski RJ, Flegal KM, Mei Z, Guo S, Wei R, et al. Centers for Disease Control and Prevention 2000 growth charts for the United States: improvements to the 1977 National Center for Health Statistics version. Pediatrics. 2002;109:45-60.

28. MacPhee AR, Andrews JJ. Risk factors for depression in early adolescence. Adolescence. 2006;41:435-66.

29. Cuijpers P, Boluijt P, van Straten A. Screening of depression in adolescents through the Internet: sensitivity and specificity of two screening questionnaires. Eur Child Adolesc Psychiatry. 2008; $17: 32-8$.

30. Dorn LD, Dahl RE, Rojahn Woodward H, Biro F. Defining the boundaries of early adolescence: a user's guide to assessing pubertal status and pubertal timing in research with adolescents. Appl Dev Sci. 2006;10:30-56.

31. Baron RM, Kenny DA. The moderator-mediator variable distinction in social psychological research: conceptual, strategic, and statistical considerations. J Pers Soc Psychol. 1986;51:1173-82.

32. Van den Hurk K, Van Dommelen P, Van Buuren S, Verkerk PH, Hirasing RA. Prevalence of overweight and obesity in the Netherlands in 2003 compared to 1980 and 1997. Arch Dis Child. 2007;92:992-5.

33. Harris MA, Prior JC, Koehoorn M. Age at menarche in the Canadian population: secular trends and relationship to adulthood BMI. J Adolesc Health. 2008;43:548-54.

34. Niven A, Fawkner S, Knowles AM, Henretty J, Stephenson C. Social physique anxiety and physical activity in early adolescent girls: the influence of maturation and physical activity motives. J Sports Sci. 2009;27:299-305.

35. Van Jaarsveld CH, Fidler JA, Simon AE, Wardle J. Persistent impact of pubertal timing on trends in smoking, food choice, activity, and stress in adolescence. Psychosom Med. 2007;69:798-806.

36. Davison KK, Susman EJ, Birch LL. Percent body fat at age 5 predicts earlier pubertal development among girls at age 9 . Pediatrics. 2003;111:815-21.
37. Prentice AM, Hennig BJ, Fulford AJ. Evolutionary origins of the obesity epidemic: natural selection of thrifty genes or genetic drift following predation release? Int J Obes. 2008;32:1607-10.

38. Ge X, Kim IJ, Brody GH, Conger RD, Simons RL, Gibbons FX, et al. It's about timing and change: pubertal transition effects on symptoms of major depression among African American youths. Dev Psychol. 2003;39:430-9.

39. Rao U, Hammen C, Ortiz LR, Chen LA, Poland RE. Effects of early and recent adverse experiences on adrenal response to psychosocial stress in depressed adolescents. Biol Psychiatry. 2008;64:521-6.

40. Ge X, Conger RD, Elder Jr GH. Pubertal transition, stressful life events, and the emergence of gender differences in adolescent depressive symptoms. Dev Psychol. 2001;37:404-17.

41. Capron C, Therond C, Duyme M. Brief report: effect of menarcheal status and family structure on depressive symptoms and emotional/behavioural problems in young adolescent girls. $\mathrm{J}$ Adolesc. 2007;30:175-9.

42. Cyranowski JM, Frank E, Young E, Shear MK. Adolescent onset of the gender difference in lifetime rates of major depression: a theoretical model. Arch Gen Psychiatry. 2000;57:21-7.

43. Hyde JS, Mezulis AH, Abramson LY. The ABCs of depression: integrating affective, biological, and cognitive models to explain the emergence of the gender difference in depression. Psychol Rev. 2008;115:291-313.

44. Dong C, Sanchez LE, Price RA. Relationship of obesity to depression: a family-based study. Int J Obes Relat Metab Disord. 2004;28:790-5.

45. Wardle J, Williamson S, Johnson F, Edwards C. Depression in adolescent obesity: cultural moderators of the association between obesity and depressive symptoms. Int J Obes. 2006;30:634-43.

46. Stice E, Cameron R, Killen J. Are naturalistic weight-reducing efforts associated with weight gain and onset of obesity in adolescent girls? West J Med. 2000;173:396.

47. Dorn LD. Measuring puberty. J Adolesc Health. 2006;39:625-6. 